\title{
FAKTOR - FAKTOR YANG MEMPENGARUHI PRODUKTIVITAS USAHATANI PEPAYA CALIFORNIA (Carica papaya L) DI DESA CIMARAGAS (Survey Pada Petani Pepaya California di Desa Cimaragas)
}

\author{
FACTORS AFFECTING CALIFORNIA PAPAYA (Carica Papaya L) \\ PRODUCTIVITY IN CIMARAGAS VILLAGE \\ (Survey on California papaya farmers in Cimaragas Village) \\ AKIK MUHAMMAD TAHKIKI* IWAN SETIAWAN² AGUS YUNIAWAN \\ ISYANTO' \\ ${ }^{1}$ Fakultas Pertanian, Universitas Galuh Ciamis \\ ${ }^{2}$ Fakultas Pertanian Universitas Padjajaran \\ $1 *$ E-mail: akiktahkiki@gmail.com
}

\begin{abstract}
ABSTRAK
Pepaya California mampu tumbuh di berbagai tempat, baik di lahan kering maupun di lahan basah dengan iklim tropis dan subtropis. Namun, produktivitasnya bervariasi untuk setiap daerah. Penelitian dilaksanakan dengan tujuan: (1) menganalisis tingkat produktivitas pepaya California, dan (2) menganalisis faktor-faktor yang berpengaruh terhadap produktivitas pepaya California. Penelitian ini didesains secara kuantitatif dengan menggunakan metode survey dengan menggunakan alat bantu kuesioner. Petani pepaya California yang dijadikan sampel penelitian berjumlah 40 orang. Analisis produktivitas usahatani pepaya California statistik deskriptif, sedangkan analisis faktor-faktor yang berpengaruh terhadap produktivitas menggunakan regresi linier berganda dengan pendugaan parameter dilakukan menggunakan SPSS 23. Hasil Penelitian menunjukkan bahwa produktivitas berkisar antara 10,00 $-16,00 \mathrm{Kw} / \mathrm{Ha}$ dengan rata-rata $12,97 \mathrm{Kw} / \mathrm{Ha}$. pupuk kandang, pengalaman berusahatani dan keanggotaan kelompok berpengaruh signifikan terhadap produktivitas usahatani papaya California, sedangkan luas lahan, benih, umur dan tingkat pendidikan tidak berpengaruh signifikan terhadap produktivitas usahatani papaya California.
\end{abstract}

Kata Kunci: usahatani, pepaya california, produktivitas, faktor-faktor

\begin{abstract}
California papaya is able to grow in various places, both on dry land and in wetland with tropical and subtropical climate. However, productivity varies from region to region. The research was conducted with the aim to know: (1) Analyzing the productivity level of California papaya, and (2) Analyze the factors influencing productivity of California papaya. This research is designed quantitatively by using a survey method using a questionnaire tool. California papaya farmers who were used as research samples amounted to 40 people. The analysis of California papaya farming productivity was descriptive statistics, while the analysis of the factors that had an effect on productivity used multiple linear regression with parameter estimation using SPSS 23. The result showed that the productivity ranged from 10,00 - 16,00 $\mathrm{Kw} / \mathrm{Ha}$ with an average of 12,97 $\mathrm{Kw} / \mathrm{Ha}$. Manure, farming experience and group membership have a significant effect on productivity of california papaya farming, while experience land area, seed, age and level of education have no significant effect to productivity of california papaya farming.
\end{abstract}

Keywords: farming, california papaya, productivity, factors 


\section{PENDAHULUAN}

Indonesia merupakan negara yang memiliki iklim tropis, berpeluang besar bagi pengembangan budidaya tanaman buah-buahan, terutama buah-buahan tropika. Buah-buahan merupakan salah satu komoditi pertanian yang terus ditingkatkan dalam hal produksinya dan sangat penting dalam pemenuhan kebutuhan konsumsi buah-buahan dalam negri sampai dengan luar negeri. Salah satu alternatif dalam hal penganekaragaman pertanian dapat dilakukan dengan adanya pengembangan usahatani pepaya california. Peningkatan kuantitas dan kualitas produksi buah pepaya dapat memberikan sumbangan yang cukup besar terhadap pendapatan petani pepaya, perluasan kesempatan kerja dan peningkatan gizi masyarakat (Febriawan, dkk 2018). Perkembangan luas lahan, produksi dan produktivitas buah pepaya di Indonesia setiap tahun masih terus berusaha untuk ditingkatkan. Desa Cimaragas memiliki luas area panen paling luas di kecamatan Cimaragas yaitu seluas 20.00 ha, produksi $161,290.00$ Ton, dan Produktivitas sebesar 80,640 ton/ha. Dari data diatas dapat dilihat bahwa produktivitas Desa Cimaragas paling tinggi dibandingkan dengan desa lainnya. Penyebab kegagalan petani dalam melaksanakan usahatani salah satunya berupa rendahnya produktivitas sebagai akibat kurangnya efisiensi dalam penggunaan faktor-faktor produksinya (Isyanto, 2012).

Hal ini melatarbelakangi dilakukannya penelitian ini dengan melihat faktor-faktor yang mempengaruhi meningkatnya produktivitas. Tujuan penelitian ini untuk mengetahui: (1) Produktivitas yang dicapai pada usahatani Pepaya California di Desa Cimaragas. (2) Pengaruh luas lahan, benih, pupuk kandang, umur, tingkat pendidikan, pengalaman berusahatani dan keanggotaan kelompok terhadap produktivitas usahatani pepaya California di Desa Cimaragas, baik secara parsial maupun simultan.

Produktivitas didefinisikan sebagai rasio dari output terhadap input. Pada kasus dimana ada satu input dan satu output, maka produktivitas dapat dihitung dengan mudah. (Sunjaya dkk, 2018). Menurut Daryanto dan Raharjo (2012), produktivitas adalah sebuah konsep yang menggambarkan hubungan antara hasil atau output (jumlah barang dan atau jasa yang diproduksi) dengan sumber yang digunakan untuk menghasilkan hasil tersebut. Menurut Handoko (2011), produktivitas adalah hubungan antara suatu masukan-masukan dan keluaran-keluaran suatu sistem produktif. Dalam teori, sering 
mudah untuk mengukur hubungan ini sebagai rasio keluaran dibagi masukan. Bila jumlah masukan sama dan lebih banyak jumlah keluaran diproduksi, maka produktivitas naik. Begitu juga, bila jumlah keluaran sama, lebih sedikit masukan digunakan, produktivitas juga naik. Pada bidang pertanian, produktivitas adalah kemampuan suatu faktor produksi (seperti luas lahan) untuk dapat memperoleh produksi yang dihasilkan per satuan luas lahan.

\section{METODE PENELITIAN}

\section{Jenis Penelitian}

Jenis penelitian yang digunakan adalah survey pada petani pepaya California di desa Cimaragas. Menurut Sugiyono (2014), survei digunakan untuk mendapatkan data dari tempat tertentu yang secara alamiah atau bukan buatan, tetapi peneliti melakukan perlakuan dalam pengumpulan data, seperti dengan mengedarkan kuesioner dan wawancara.

\section{Teknik Penarikan Sampel}

Teknik penarikan sampel penelitian ini dilakukan secara purposive sampling dengan penentuan sampel secara sensus yang berarti mengambil seluruh petani pepaya California, populasi petani pepaya California di desa Cimaragas. Menurut Arikunto (2006), jika jumlah subjek kurang dari 100 orang sebaiknya diambil semuanya, jika subjeknya besar/lebih dari 100 orang dapat diambil sebagian atau sekitar $10-15 \%$ atau $20-25 \%$ atau lebih.

\section{Teknik Pengumpulan Data}

Data yang dikumpulkan dalam penelitian ini meliputi data primer dan data sekunder. Pengumpulan data primer diperoleh melalui observasi dan wawancara langsung dengan petani di Desa Cimaragas Kecamatan Cimaragas Kabupaten Ciamis. Sedangkan Sumber data sekunder digunakan untuk mendukung informasi yang didapatkan dari sumber data primer yaitu dari litelatur, bahan pustaka, buku-buku, penelitian terdahulu, dan dari data dinas atau instansi terkait yang ada hubungannya dengan penelitian yang dilakukan.

\section{Rancangan Analisis Data}

Menurut Rafeah (2013) Produktivitas usahatani pepaya California di Desa Cimaragas Kec. Cimaragas, Kabupaten Ciamis dapat dihitung dengan produktivitas lahan dengan menggunakan persamaan sebagai berikut:

$$
\text { Produktivitas }=\frac{\text { Produksi }(K w)}{\text { Luas Lahan }(h a)}
$$

Faktor-faktor yang mempengaruhi produktivitas usahatani pepaya California menggunakan analisis regresi linier berganda dengan dilakukan pendugaan parameter regresi linier berganda 
menggunakan program SPSS versi 25 . Dengan model analisis linier berganda sebagai berikut:

$Y=a+b_{1} X_{1}+b_{2} X_{2}+\ldots \ldots+b_{i} X_{n}+\mathrm{e}$

Model persamaan regresi yang digunakan untuk menganalisis faktorfaktor yang berpengaruh terhadap produktivitas usahatani pepaya California adalah sebagai berikut:

$Y=a+b_{1} X_{1}+b_{2} X_{2}+b_{3} X_{3}+b_{4} X_{4}+$ $b_{5} X_{5}+b_{6} X_{6}+b_{7} X_{7}+\mathrm{e}$

\section{Dimana:}

$\mathrm{Y}=$ Produktivitas usahatani pepaya California (kg/ha)

$\mathrm{X}_{1}=$ Luas lahan (ha)

$\mathrm{X}_{2}=$ Benih (pohon)

$\mathrm{X}_{3}=$ Pupuk kandang $(\mathrm{kg})$

$\mathrm{X}_{4}=$ Umur petani (tahun)

$\mathrm{X}_{5}=$ Pendidikan petani (tahun)

$\mathrm{X}_{6}=$ Pengalaman berusahatani (tahun)

$\mathrm{X}_{7}=$ Keanggotaan kelompok (1 jika menjadi anggota kelompok, 0 jika tidak)

$\mathrm{b}_{\mathrm{i}} \quad=$ Koefisien regresi

Uji $F$ atau koefisien regresi secara bersama-sama digunakan untuk mengetahui apakah secara bersama-sama variabel independen atau variabel bebas berpengaruh terhadap variabel dependen atau variabel terikat. Adapun kriteria pengambilan keputusan sebagai berikut: $H_{0}$ ditolak jika $\mathrm{F}$ hitung $>\mathrm{F}$ tabel atau $\mathrm{F}$ significance $\leq(\alpha=0,05)$
$H_{0}$ diterima jika $\mathrm{F}$ hitung $<\mathrm{F}$ table atau $\mathrm{F}$ significance $>(\alpha=0,05)$

Uji $\mathrm{t}$ berarti melakukan pengujian terhadap koefisien secara parsial. Pengujian ini dilakukan untuk mengetahui signifikansi peranan variabel bebas terhadap variabel terikat yang diuji dengan uji-t satu, dengan tingkat kesalahan 5\% dan dengan taraf kepercayaan 95\%, pengambilan keputusan untuk melakukan penerimaan atau penolakan setiap hipotesis dengan kriterianya adalah dengan cara melihat signifikansi harga $t$ hitung setiap variabel independen atau membandingkan nilai $\mathrm{t}$ hitung dengan nilai yang ada pada $\mathrm{t}$ tabel, maka Ha diterima dan sebaiknya $t$ hitung tidak signifikan dan berada dibawah t tabel, maka Ha ditolak. Kaidah keputusan:

- Tolak $H_{0}$ (terima Ha), jika t hitung > t tabel

- Terima $H_{0}$ (tolak Ha), jika t hitung $<\mathrm{t}$ tabel

Semua data terlebih dahulu harus dianalisis dengan uji normalitas data (Priyatno, 2011) dan dilakukan uji asumsi klasik (Salvatore, 2005; Priyatno, 2011).

\section{HASIL DAN PEMBAHASAN}

\section{Identitas Responden}

Berdasarkan hasil penelitian yang telah dilakukan diketahui bahwa seluruh 
responden yang diteliti berada pada kelompok usia produktif (15-64 tahun). Sebagian besar responden sebanyak 38 orang (95\%) berpendidikan menengah, baik SMP maupun SMA, dan sisa 2 orang (5\%) berpendidikan SD dengan pengalaman berusahatani berkisar antara 615 tahun. Sebagian besar petani memiliki luas lahan garapan untuk pepaya California di bawah 0,5 ha, artinya luas lahan garapan usahatani pepaya California di Desa Cimaragas didominasi oleh golongan luas lahan sempit.

Tingkat Produktivitas Usahatani Pepaya

\section{California}

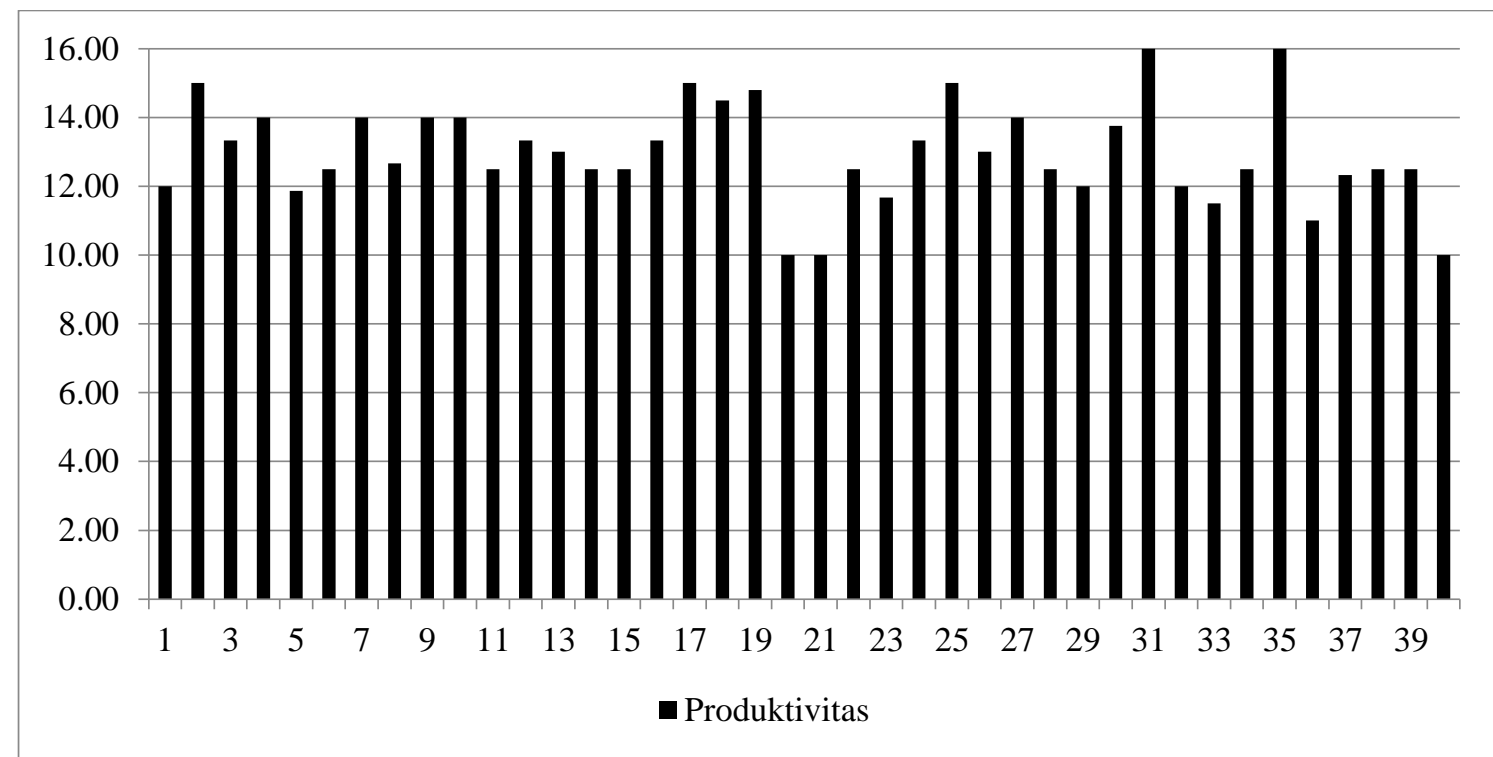

Gambar 1. 
Faktor-Faktor Yang Berpengaruh Terhadap Produktivitas Pepaya

\section{California}

Faktor - faktor yang berpengaruh terhadap produktivitas dimaksudkan untuk mengetahui variabel - variabel apa saja yang mempengaruhi produktivitas usahatani pepaya California, untuk membahas produktivitas maka peneliti menggunakan tujuh variabel, adapun variabel tersebut diantaranya luas lahan, benih, pupuk kandang, umur, tingkat pendidikan, pengalaman berusahatani, dan keanggotaan kelompok. Analisis faktor faktor yang berpengaruh terhadap produktivitas usahatani pepaya California disajikan pada tabel 1 .

Tabel 1. Faktor-Faktor Yang Berpengaruh Terhadap Produktivitas Pepaya California

\begin{tabular}{lrrcc}
\hline \multicolumn{1}{c}{ Variabel } & Koefisien & $\begin{array}{c}\text { Standard } \\
\text { Error }\end{array}$ & t-ratio & Sig. \\
\hline Konstanta & 0,747 & 0,065 & 11,506 & $0,000^{*}$ \\
Luas lahan & $-0,002$ & 0,005 & $-0,337$ & $0,738^{\mathrm{ns}}$ \\
Benih & $-0,009$ & 0,008 & $-1,249$ & $0,221^{\mathrm{ns}}$ \\
Pupuk kandang & 0,054 & 0,009 & 6,036 & $0,000^{*}$ \\
Umur & 0,056 & 0,055 & 1,249 & $0,312^{\mathrm{ns}}$ \\
Tingkat pendidikan & $-0,036$ & 0,045 & $-0,794$ & $0,433^{\text {ns }}$ \\
Pengalaman berusahatani & 0,108 & 0,028 & 3,822 & $0,001^{* *}$ \\
Keanggotaan kelompok & 0,024 & 0,008 & 3,064 & $0,004^{* *}$ \\
\hline
\end{tabular}

$\mathrm{R}^{2}=0,979$

F-hitung $=214,521 *$

Sumber: Analisis Data Primer, 2020

Keterangan: *: nyata pada $\alpha 1 \%$, ${ }^{* *}$; nyata pada $\alpha 5 \%$, ns: tidak signifikan

Koefisien determinasi $\left(R^{2}\right)$ sebesar 0,979 atau 97,9 \%. Hal ini menunjukkan bahwa variabel independen yaitu luas lahan, pupuk kandang, benih, umur, tingkat pendidikan, pengalaman berusahatani, dan keanggotaan dalam kelompok mampu menjelaskan sebesar $97,9 \%$ variasi nilai produktivitas usahatani pepaya California di Desa Cimaragas sedangkan sisanya sebesar 2,1\% dijelaskan oleh variabel lain yang tidak terdapat dalam model persamaan.
Secara parsial faktor - faktor yang berpengaruh positif dan signifikan terhadap produktivitas meliputi: pupuk kandang, pengalaman berusahatani dan keanggotaan kelompok. Sedangkan faktor - faktor produktivitas yang tidak berpengaruh signifikan namun positif adalah umur. Sementara variabel luas lahan, benih dan tingkat pendidikan berpengaruh negatif dan tidak signifikan. Secara simultan semua variabel yang terdiri dari luas lahan, benih, pupuk 
kandang, umur, tingkat pendidikan, pengalaman berusahatani dan keanggotaan kelompok berpengaruh signifikan.

\section{KESIMPULAN}

1. Produktivitas usahatani pepaya California berkisar antara 10,00-16,00 $\mathrm{kw} / \mathrm{ha}$ dengan rata-rata $12,97 \mathrm{kw} / \mathrm{ha}$.

2. Pupuk kandang, pengalaman berusahatani dan keanggotaan kelompok berpengaruh signifikan terhadap produktivitas usahatani pepaya California; sedangkan luas lahan, benih, umur dan tingkat pendidikan tidak berpengaruh signifikan.

\section{SARAN}

1. Pupuk kandang yang berpengaruh terhadap produktivitas mengindikasikan rendahnya kandungan unsur hara dalam tanah yang digunakan pada usahatani pepaya California di Desa Cimaragas. Oleh karena itu, perlu dipertahankan pemberian pupuk kandang untuk menjaga unsur hara yang diperlukan pada usahatani pepaya California.

2. Pendidikan non formal perlu diberikan kepada petani melalui kegiatan penyuluhan dan bimbingan teknis untuk meningkatkan pengetahuan, keterampilan teknis dan pengalaman petani dalam melaksanakan usahatani pepaya California.

3. Mengingat keanggotaan kelompok berpengaruh signifikan terhadap produktivitas, maka peningkatan pendidikan non formal petani maupun kegiatan lain dalam upaya peningkatan pengetahuan dan keterampilan teknis petani perlu melibatkan kelompok secara aktif.

\section{DAFTAR PUSTAKA}

Arikunto, Suharsimi. 2006. Prosedur Penelitian : Suatu Pendekatan Praktik Revisi IV. Jakarta : PT Rineka Cipta.

Daryanto dan Raharjo, M. 2012. Model Pembelajaran Inofatif. Yogyakarta: Gava Media.

Febriawan, G., dkk. 2018. Analisis Faktorfaktor Yang Mempengaruhi Risiko Produksi Usahatani Pepaya di Kecamatan Ledokombo Kabupaten Jember. Jurnal Agribest Vol 02, No 02.

Handoko, T.H. 2011. Manajemen Personalia dan Sumberdaya Manusia. Yogyakarta: Penerbit BPFE.

Isyanto, A.Y. 2012. Faktor-faktor Yang Berpengaruh Terhadap Produksi Pada Usahatani Padi di Kabupaten Ciamis. Cakrawala Galuh, 1(8): 18.

Priyatno, Duwi. 2011, Buku Saku Analisis Statistik Data SPSS, Mediakom, Yogyakarta.

Rafeah. 2013. Produktivitas dan Kelayakan Ekonomis Usahatani Semangka Pada Lahan Tipe C Rawa Pasang Surut Musim Kemarau di Desa 
Telang Kecamatan Muara Telang Kabupaten Banyu Asin.

Sugiyono. 2014. Metode Penelitian Pendidikan Pendekatan Kuantitatif, Kualitatif dan $R$ \& D. Bandung: Alfabeta.
Sunjaya, D. H., Hardiyanto, T. dan Agus, Y. I. 2018. Faktor - Faktor Yang Berpengaruh Terhadap Produktivitas Usahatani Minapadi di Kota Tasikmalaya. Jurnal Pemikiran Masyarakat Ilmiah Berwawasan Agribisnis. 